\title{
ŪMINIO SKAUSMO RIZIKOS VEIKSNIAI PUNKCIJOS VIETOJE PO PERKUTANINĖS KORONARINĖS INTERVENCIJOS
}

\author{
Liuda Brogienè ${ }^{1}$, Lolita Grygalyte் ${ }^{2}$, Benas Kakta ${ }^{2}$, Andrius Macas ${ }^{1}$ \\ ${ }^{\prime}$ Lietuvos sveikatos moksly universiteto ligonine Kauno klinikos, Anesteziologijos klinika, \\ ${ }^{2}$ Lietuvos sveikatos moksly universitetas, Medicinos akademija, Medicinos fakultetas
}

Raktažodžiai: ūminis skausmas, poprocedūrinis skausmas, ūminio skausmo rizikos veiksniai, perkutaninè koronarinè intervencija.

\section{Santrauka}

Tikslas. Nustatyti ūminio rankos skausmo po perkutaninès koronarinès intervencijos rizikos veiksnius.

Metodika. Atliktas perspektyvusis stebejimo tyrimas. Ištirti 136 pacientai, stacionarizuoti į Lietuvos sveikatos mokslų universiteto ligoninès Kauno klinikų (LSMUL KK) Kardiologijos kliniką atlikti perkutaninę koronarinę intervenciją 2018-2020 metais. Surinkti tiriamujų demografiniai duomenys, procedūros metu stebètas arterinis kraujospūdis (AKS) ir širdies susitraukimų dažnis (ŠSD). Pacientų paprašyta skausmą ịvertinti nuo 0 iki 10 skaitinèje skausmo skaleje procedūros metu, 2 val., 12 val., 24 val. ir 48 val. po procedūros. Gauti duomenys išanalizuoti statistiniais metodais.

Rezultatai. Moterys nurodè didesnius skausmo balus visuose vertintuose laiko taškuose: intervencijos metu, po 2 val., po 12 val., po 24 val. ir po 48 val. ( $\mathrm{p}=0,003$, $\mathrm{p}<0,001, \mathrm{p}=0,010, \mathrm{p}=0,022$ ir $\mathrm{p}=0,048$ atitinkamai). Moteriškoji lytis buvo skausmo rizikos veiksnys procedūros metu ( $\mathrm{p}=0,018), 2$ val. $(\mathrm{p}=0,008), 12$ val., $(\mathrm{p}=0,023), 24$ val. $(p=0,045)$ ir 48 val. po procedūros $(p=0,046)$. Ūminiam skausmui po 24 val. ịtakos turejjo cukrinis diabetas (SD), $(\mathrm{p}=0,041)$. Dislipidemija turejo įtakos skausmui procedūros metu ( $\mathrm{p}=0,024)$, po 12 val. $(\mathrm{p}=0,018)$, po 24 val. $(p=0,028)$. Didesnis sistolinis AKS buvo susijęs su skausmu procedūros metu $(\mathrm{p}=0,022)$.

Išvados. Moterys procedūros metu ir po jos skausmą įvertino didesniais balais. Ūminio skausmo rizikos veiksniai transradialinės PKI metu ir po jos buvo moteriškoji lytis, dislipidemija ir cukrinis diabetas.

\section{İvadas}

Per pastarajị dešimtmetị perkutaninè koronarinè inter- vencija (PKI) tapo pagrindiniu kraujotakos atkūrimo metodu Europoje [1]. Nuo 1977 metų tradicinis pirmojo pasirinkimo kateterio įterpimo kelias buvo per šlaunies arteriją (transfemoraliai). Nors šis kelias patogus dèl šlaunies arterijos dydžio, tačiau siejamas su padidèjusia kraujagyslinių komplikacijų (pseudoaneurizmų, arterioveninių fistulių, didelio kraujavimo) rizika, ilgesniu stacionarizavimo laikotarpiu [2]. Pastaruoju metu populiareja PKI atlikimas per stipininę arteriją (transradialinis kelias). Daugejja įrodymų, kad procedūrai renkantis stipininę arteriją, sumažèja gausaus kraujavimo ir ateroembolinių inkstų kraujagyslių komplikacijų rizika [3]. Nors PKI per stipininę arteriją turi daug privalumų, tačiau galimos ir komplikacijos, tokios kaip dūrio vietos kraujavimas, stipininès arterijos okliuzija ir kraujosruvos susidarymas. Kadangi stipininè arterija yra siauresnè už šlaunies arteriją, manipuliacijos dažniau gali sukelti punkcijos vietos skausmą [4].

Ūminis skausmas yra normalus atsakas ị medicininę intervenciją. Jis kyla dèl audinių traumos metu išlaisvintų uždegiminių mediatorių, kurie sukelia padidejusio jautrumo reakcijas i pažeidimo vietoje atliekamus veiksmus. Stiprus skausmas gali būti susijęs su ilgesniu gijimo laikotarpiu, ilgesne stacionarizavimo trukme, paciento nepasitenkinimu ar ūminio skausmo peréjimu ị lètinị [5]. Dauguma tyrimų vertina ūmini skausmą ir jo rizikos veiksnius po didelès apimties operacijų, o skausmas po mažiau invazinių procedūrų, tokių kaip PKI, nèra pakankamai išanalizuotas. Literatūros duomenimis, galimi ūminio skausmo rizikos veiksniai po transradialinès PKI yra lytis, kateterio dydis, kūno masès indeksas, amžius, pakartotinai atliekama procedūra, procedūros trukmè [4]. Ūminio skausmo rizikos veiksnių atpažinimas po transradialinès PKI galètų padèti sveikatos priežiūros specialistams geriau numatyti gydymo taktiką, taip užtikrinant kokybišką paciento priežiūrą.

Tyrimo tikslas - nustatyti reikšmingus ūminio punkcijos vietos skausmo rizikos veiksnius po perkutaninès koronarinès intervencijos per stipininę arteriją. 


\section{Tyrimo medžiaga ir metodai}

Atliktas perspektyvusis stebejjimo tyrimas. Tyrimui atlikti gautas regioninis bioetikos leidimas Nr. BE-2-7, 2018-02-26. İtraukimo kriterijai: 1) pacientai stacionarizuoti ị LSMUL KK Kardiologijos kliniką perkutaninei koronarinei intervencijai 2018-2020 metų laikotarpiu; 2) abiejų lyčių, vyresni nei 18 metu pacientai; 3) sąmoningi pacientai, kurie sutiko dalyvauti tyrime ir pasirašè sutikimo formą. Remiantis šiais kriterijais, buvo atrinkti 137 pacientai, 1 paciento nepavyko apklausti po 48 valandų, ị tyrimą iš viso įtraukti 136 pacientai. Tiriamieji procedūros dieną buvo apklausti, gautas raštiškas sutikimas dalyvauti tyrime, surinkti duomenys apie

1 lentelè. Tiriamosios imties charakteristikos.

Kokybiniai dydžiai aprašyti pateikiant ju reikšmiụ dažnị ir santykinị dažnị (\%), kiekybiniai kintamieji nurodyti kaip vidurkis \pm standartinis nuokrypis (SN). KMI - kūno masès indeksas.

\begin{tabular}{|l|c|}
\hline Imties charakteristikos (n=136) & $\begin{array}{c}\text { Reikšmės n (\%) } \\
\text { arba vidurkis } \mathbf{\pm S N}\end{array}$ \\
\hline Lytis & $90(66,2)$ \\
Vyras & $46(33,8)$ \\
Moteris & $64,43 \pm 11,33$ \\
\hline Amžius & $28,91 \pm 5,30$ \\
\hline KMI kg/m² & $41(30,1)$ \\
\hline Rūkymas & $20(14,7)$ \\
\hline Cukrinis diabetas & $122(89,7)$ \\
\hline Arterinè hipertenzija & $80(58,8)$ \\
\hline Dislipidemija & \\
\hline Procedūros skubumas & $27(19,9)$ \\
skubioji & $109(80,1)$ \\
planinè & $35,02 \pm 21,16$ \\
\hline Procedūros trukmè (minutėmis) & \\
\hline Kelintą kartą atlikta procedūra & $81(59,6)$ \\
1 & $38(27,9)$ \\
2 & $9(6,6)$ \\
3 & $5(3,7)$ \\
4 & $2(1,5)$ \\
5 & $1(0,7)$ \\
\hline 6 & $152,26 \pm 24,74$ \\
\hline sAKS procedūros metu & $78,89 \pm 11,05$ \\
\hline dAKS procedūros metu & $72,61 \pm 12,96$ \\
\hline ŠSD procedūros metu & \\
\hline
\end{tabular}

2 lentelè. Skausmo vertinimo palyginimas tarp vyrų ir moterų. Rezultatai pateikiami medianomis ir pirmuoju-trečiuoju kvartiliais (Q1-Q3).

\begin{tabular}{|l|l|l|l|}
\hline $\begin{array}{l}\text { Skausmo vertini- } \\
\text { mas }\end{array}$ & \multicolumn{2}{|l|}{ Lytis } & \multirow{2}{*}{ p reikšmé } \\
\cline { 2 - 4 } & vyras $(\mathrm{n}=90)$ & moteris $(\mathrm{n}=46)$ & \\
\hline Intervencijos metu & $0(0-3)$ & $3(0-6)$ & $\mathbf{0 , 0 0 3}$ \\
\hline po 2 val. & $2(0-4)$ & $4(2-6)$ & $<\mathbf{0 , 0 0 1}$ \\
\hline po 12 val. & $0(0-3)$ & $2(0-4)$ & $\mathbf{0 , 0 1 0}$ \\
\hline po 24 val. & $0(0-0,25)$ & $1(0-2)$ & $\mathbf{0 , 0 2 2}$ \\
\hline po 48 val. & $0(0-0)$ & $0(0-1)$ & $\mathbf{0 , 0 4 8}$ \\
\hline
\end{tabular}

amžių, lytị, KMI, gretutines ligas. Pasižymètas procedūros skubumas (skubi ar planinè), trukmè, procedūros metu stebètas paciento arterinis kraujospūdis ir ŠSD. Pacientų paprašyta skausmą įvertinti nuo 0 iki 10 skaitinejje skausmo skalejje $(0$ - nejaučia skausmo, 10 - nepakeliamas skausmas) procedūros metu, 2 val., 12 val., 24 val. ir 48 val. po procedūros.

Tiriamujų duomenų statistinè analizè atlikta naudojant duomenų analizès paketą IBM SPSS 26.0. Imties duomenu normalumo pasiskirstymas patikrintas naudojant ShapiroWilk testą. Skausmo vertinimo reikšmių pasiskirstymas netenkino normalumo sąlygų, reikšmių palyginimas tarp lyčių atliktas naudojant neparametrinị Mann-Whitney U testą, rezultatai pateikiami medianomis ir pirmuoju-trečiuoju kvartiliais (Q1-Q3). Siekiant nustatyti nepriklausomus rizikos veiksnius, statistiškai reikšmingai darančius įtaką ūminiam skausmui, atlikta logistinè regresija.

Kiekybiniai dydžiai aprašyti pateikiant požymių reikšmių vidurki \pm standartinis nuokrypis. Kokybiniai dydžiai aprašyti pateikiant jų reikšmių dažnị ir santykinị dažnị (\%). Rezultatai laikyti statistiškai reikšmingais, kai $\mathrm{p}<0,05$.

\section{Tyrimo rezultatai}

Ištirti 136 pacientai, iš jų 90 (66,2\%) vyrų ir 46 (33,8\%) moterys. Vidutinis tiriamujų amžius $64,43 \pm 11,33$ metai. Tiriamosios imties charakteristikos pateiktos 1 lentelèje.

Vidutinis skausmo intensyvumas balais pagal skaitinę skausmo skalę intervencijos metu buvo $2,23 \pm 2,57$, po 2 val.

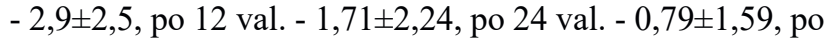
48 val. - $0,54 \pm 1,43$. Skausmo intensyvumo kitimas iki 48 val. po intervencijos pavaizduotas 1 paveiksle.

Palyginus vidutinị vyrų ir moterų skausmo intensyvumą nustatyta, kad statistiškai reikšmingai didesnius skausmo balus nurodè moterys visuose vertintuose laiko taškuose: intervencijos metu, po 2 val., po 12 val., po 24 val. ir po 48 val. ( $p=0,003, p<0,001, p=0,010, p=0,022$ ir $p=0,048$ atitinkamai). Skausmo vertinimo palyginimas tarp lyčių pateikiamas 2 lenteleje.

Atlikta vienfaktorinès logistinès regresijos analizè, siekiant nustatyti kintamųjų galimą įtaką poprocedūriniam skausmui. Skausmo jutimo procedūros metu didesnès rizikos veiksniai buvo moteriškoji lytis ir dislipidemija $(p<0,05)$. Didesnis sAKS procedūros metu buvo susijęs su didesniu skausmo jutimu ( $\mathrm{p}=0,022)$. Didesnè skausmo jutimo rizika praejus 2 valandoms po procedūros, nustatyta tik moterims $(\mathrm{p}=0,008)$. Didesniam skausmo jutimui praejus 12 valandu po procedūros įtakos turèjo moteriškoji lytis ir dislipidemija $(\mathrm{p}<0,05)$. Jausti skausmą praejjus 24 valandoms po procedūros, didesnę riziką turèjo moterys, sergantys CD ar dislipidemija $(\mathrm{p}<0,05)$. Praejus 48 valandoms po procedūros, didesnè skausmo rizika nustatyta tik moterims $(\mathrm{p}=0,046)$. 
Visi statistiškai reikšmingą itaką turinčių kintamuju vienfaktoriniai modeliai buvo ịvertinti kaip reikšmingi $(\mathrm{p}<0,05)$. Kitos anksčiau pateiktos charakteristikos reikšmingos įtakos neturèjo nei viename laiko taške $(p>0,05)$. Gautieji rezultatai pateikiami 3 lentelèje.

\section{Diskusija}

Lyčių skirtumai skausmo jutimo ir suvokimo atžvilgiu yra senai žinomi, tačiau vis dar sulaukia tyrejjų dèmesio. Gilèjantis supratimas apie lytinių hormonu bei oksitocino poveiki centrinei ir periferinei nervų sistemoms skatina ieškoti galimo šių ryšiu pritaikymo analgezijoje [6]. A. Lindner ir bendraautoriai tyrime su pacientais, kuriems atliktos ịvairios transkutaninès intervencijos, nustatè, kad moterys jaučia didesnị skausmą, nei vyrai [7]. Tuo tarpu Ø. Holme ir bendraautorių tyrime su pacientais, kuriems atlikta kolonoskopija netaikant sedacijos, buvo išsiaiškinta, kad moteriškoji lytis yra vienas iš nepriklausomų skausmo jutimo rizikos veiksnių [8]. Mūsų atliktame tyrime taip pat nustatyta, kad moteru skausmo

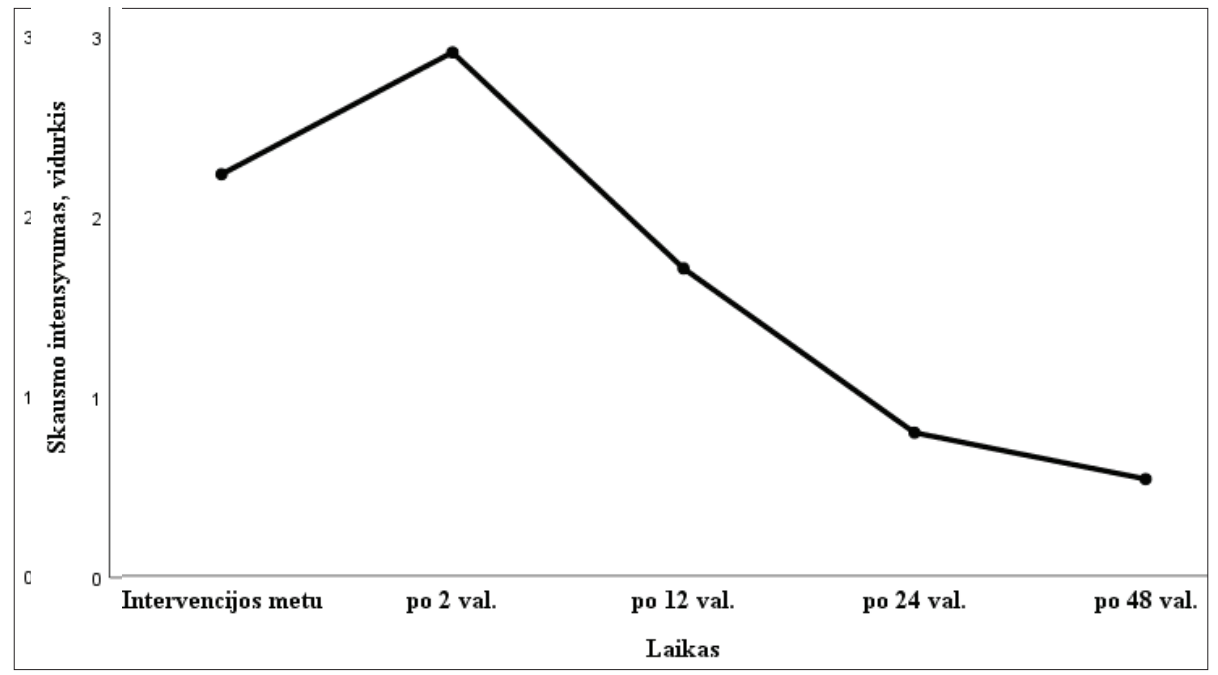

1 pav.Vidutinio skausmo intensyvumo kitimas iki 48 val. po intervencijos.

jutimo rizika visuose mūsų tirtuose laiko taškuose buvo du kartus didesnè, negu vyrų. Šie mūsų tyrimo ir kitų anksčiau aptartų tyrimų rezultatai atkreipia demesị i lytị kaip ị svarbų ir lengvai nustatomą poprocedūrinio skausmo rizikos veiksnị.

Šiame tyrime nustatème, kad reikšmingas ūminio skausmo 24 val. po procedūros rizikos veiksnys buvo cukrinis diabetas. Viena iš priežasčių, galinti daryti ịtaką didesniam skausmo jutimui, gali būti diabetinè polineuropatija,

3 lentelè. Kintamieji ir jų galimybių santykių (GS) vertès, prognozuojant ūminio poprocedūrinio skausmo jutimą.

$P I$ - pasikliautinasis intervalas, IŠL - išeminé širdies liga, CD - cukrinis diabetas, AH - arterine hipertenzija, sAKS - sistolinis arterinis kraujospüdis, dAKS - diastolinis arterinis kraujospüdis, ŠSD - širdies susitraukimu dažnis.

\begin{tabular}{|c|c|c|c|c|c|c|c|c|c|c|c|c|c|c|c|}
\hline \multirow{3}{*}{$\begin{array}{l}\text { Rizikos } \\
\text { veiksniai }\end{array}$} & \multicolumn{15}{|c|}{ Ūminio skausmo pasireiškimas } \\
\hline & \multicolumn{3}{|c|}{ procedūros metu } & \multicolumn{3}{|c|}{ po 2 val. } & \multicolumn{3}{|c|}{ po 12 val. } & \multicolumn{3}{|c|}{ po 24 val. } & \multicolumn{3}{|c|}{ po 48 val. } \\
\hline & GS & $95 \%$ PI & $\mathrm{p}$ & GS & $95 \%$ PI & $\mathrm{p}$ & GS & $95 \%$ PI & $\mathrm{p}$ & GS & $95 \%$ PI & $\mathrm{p}$ & GS & $95 \%$ PI & $\mathrm{p}$ \\
\hline Lytis & 2,411 & $1,16-4,99$ & 0,018 & 3,678 & $1,41-9,61$ & 0,008 & 2,344 & $1,12-4,89$ & 0,023 & 2,175 & $1,02-4,64$ & 0,045 & 2,535 & $1,02-6,31$ & 0,046 \\
\hline IŠL trukmè & 0,947 & $0,88-1,01$ & 0,117 & 1,014 & $0,94-1,09$ & 0,713 & 0,988 & $0,93-1,05$ & 0,715 & 1,010 & $0,94-1,08$ & 0,765 & 0,961 & $0,87-1,06$ & 0,417 \\
\hline KMI & 0,959 & $0,9-1,03$ & 0,217 & 0,940 & $0,88-1,01$ & 0,084 & 0,956 & $0,9-1,02$ & 0,178 & 0,976 & $0,91-1,05$ & 0,509 & 0,911 & $0,82-1,01$ & 0,072 \\
\hline Rūkymas & 1,286 & $0,62-2,68$ & 0,504 & 1,296 & $0,56-3$ & 0,545 & 1,305 & $0,62-2,73$ & 0,479 & 0,554 & $0,24-1,3$ & 0,174 & 0,594 & $0,2-1,73$ & 0,339 \\
\hline $\mathrm{CD}$ & 0,693 & $25-1,89$ & 0,473 & 0,677 & \begin{tabular}{|c|}
$0,25-1,85$ \\
\end{tabular} & \begin{tabular}{|l|}
0,448 \\
\end{tabular} & 1,181 & $0,46-3,06$ & 0,733 & 2,742 & $1,04-7,22$ & 0,041 & 1,815 & $0,59-5,62$ & 301 \\
\hline $\mathrm{AH}$ & 1,075 & $0,35-3,29$ & 0,900 & 1,035 & $0,3-3,53$ & 0,956 & 0,775 & $0,25-2,37$ & 0,655 & 2,819 & $0,6-13,21$ & 0,188 & 2,860 & $\begin{array}{l}0,36- \\
23,02\end{array}$ & 0,323 \\
\hline $\begin{array}{l}\text { Dislipi- } \\
\text { demija }\end{array}$ & 2,272 & $1,11-4,64$ & 0,024 & 1,914 & $0,9-4,08$ & 0,093 & 2,318 & $1,15-4,66$ & 0,018 & 2,455 & $1,1-5,46$ & 0,028 & 1,385 & $0,54-3,53$ & 0,495 \\
\hline Amžius & 1,005 & $0,98-1,04$ & 0,740 & 1,021 & $0,99-1,05$ & \begin{tabular}{|l|}
0,230 \\
\end{tabular} & 1,013 & $0,98-1,04$ & 0,408 & 1,013 & $0,98-1,05$ & 0,436 & 1,005 & $0,97-1,05$ & 0,792 \\
\hline $\begin{array}{l}\text { Procedūros } \\
\text { skubumas }\end{array}$ & 1,205 & $0,52-2,81$ & 0,665 & 1,455 & $0,54-3,94$ & 0,461 & 1,796 & $0,76-4,27$ & 0,185 & 1,480 & $0,61-3,59$ & 0,385 & 1,149 & $0,38-3,43$ & 0,804 \\
\hline $\begin{array}{l}\text { Procedūros } \\
\text { trukmè }\end{array}$ & 1,000 & $0,98-1,02$ & 0,961 & 0,997 & $0,98-1,01$ & 0,757 & 0,998 & $0,98-1,01$ & 0,766 & 1,014 & $1-1,03$ & 0,101 & 1,010 & $0,99-1,03$ & 0,309 \\
\hline sAKS & 1,018 & $1,00-1,03$ & 0,022 & 0,997 & 0,98-1,01 & 0,738 & 1,011 & $1-1,03$ & 0,126 & 1,009 & $0,99-1,02$ & 0,242 & 1,012 & $0,99-1,03$ & 0,176 \\
\hline dAKS & 1,016 & $0,98-1,05$ & 0,337 & 0,984 & $0,95-1,02$ & \begin{tabular}{|l|}
0,349 \\
\end{tabular} & 1,000 & $0,97-1,03$ & 0,984 & 1,025 & $0,99-1,06$ & 0,143 & 1,025 & $0,99-1,07$ & 0,220 \\
\hline ŠSD & 0,998 & $0,97-1,02$ & 0,883 & 0,979 & $0,95-1,01$ & \begin{tabular}{|l|}
0,152 \\
\end{tabular} & 0,992 & $0,97-1,02$ & 0,544 & 0,994 & $0,97-1,02$ & 0,664 & 0,966 & $0,93-1$ & 0,086 \\
\hline $\begin{array}{l}\text { Kelintą } \\
\text { kartą atlikta } \\
\text { procedūra }\end{array}$ & 0,701 & $0,47-1,05$ & 0,082 & 0,942 & $0,64-1,38$ & 0,760 & 0,992 & $0,7-1,41$ & 0,966 & 1,144 & $0,79-1,66$ & 0,474 & 0,871 & $0,52-1,46$ & 0,599 \\
\hline
\end{tabular}


kuri yra viena iš dažniausių lėtinių mikrovaskulinių diabeto komplikacijų, paveikianti tiek 1 tipo $\mathrm{CD}$, tiek 2 tipo $\mathrm{CD}$ pacientus. Diabetinès neuropatijos kyla dèl lètinès hiperglikemijos, mikrovaskulinio nepakankamumo, oksidacinio streso ir autoimuninès nervų pažaidos [9]. Maždaug trečdaliui pacientų, kuriems išsivysto diabetinè polineuropatija, pasireiškia skausminga distalinè diabetinè neuropatija. Esant šiai patologijai, labiau pažeidžiamos smulkiosios nervinès skaidulos, o būdingi nusiskundimai: deginimas, duriantis ar dilgčiojantis skausmas, alodinija (skausminga reakcija i dirgiklius, kurie paprastai skausmo nesukelia) ir hiperalgezija (sustipreję̨s skausmo jutimas) [10]. Sergant cukriniu diabetu, pažeidžiamos ir kraujagyslès. Esant lètinei hiperglikemijai, dislipidemijai ir insulino atsparumui, dideja aterogeninių mažo tankio lipoproteinų, pažangių galutinių glikavimo produktų ir uždegimą skatinančių citokinų aktyvacija - visi šie veiksniai skatina arterijų vidinès sienelès pažaidą ir aterosklerozinių plokštelių formavimąsi, kas galètų lemti didesnę stipininès arterijos pažaidą ir didesnį skausmo jutimą po PKI [11]. S. Dharma ir bendraautorių atliktame tyrime nustatyta, kad pacientai, kurie jautė rankos skausmą po transradialinès PKI, dažniau anamnezèje nurode $C D$, tačiau šie rezultatai nebuvo statistiškai reikšmingi [12]. Ne visiems CD pacientams pasireiškia skausminga diabetinè neuropatija ar kraujagyslių pažaida, kas gali lemti skirtingus tyrimų rezultatus. Šiame tyrime pacientai iki procedūros nenurode skausmo galūnèje, todèl tikètina, kad didesnę įtaką skausmo jutimui turejjo kraujagyslių pažaida dèl persistuojančios hiperglikemijos ir dislipidemijos.

Dislipidemijos, ypač hipercholesterolemija, jau seniai žinomos kaip reikšmingi etiologiniai aterosklerozès vystymosi veiksniai. Ši liga labiausiai pažeidžia arterijų vidinị sluoksnị - intimą [13]. Atliekant PKI transradialiniu keliu, iš punkcijos srityje esančių struktūrų stipininè arterija pažeidžiama labiausiai. Kaip žinoma, ūminis skausmas yra tiesioginè audinių vientisumo ir struktūriškumo pažaidos pasekmè, todèl galima manyti, kad skausmo pojūtis priklausys ir nuo audinių būklès iki pažeidimo. K. Yano ir bendraautoriai, atlikę retrospektyvini tyrimą su pacientais, kuriems atliekamos rankos operacijos dèl tunelinio riešo sindromo, nustatè, kad hipercholesterolemija susijusi su subjektyviomis pooperacinèmis baigtimis, tarp jų ir skausmo jutimu [14]. Mūsų tyrimas taip pat parodé, kad pacientų, kuriems nustatyta dislipidemija, didesnè skausmo rizika transradialinès PKI procedūros metu bei praejjus 12 ir 24 valandoms po jos. Hipercholesterolemija ir kitos dislipidemijos sukelia stipininès arterijos pažaidą, sustandina arterijos intimą ir kraujagyslè tampa lengviau pažeidžiama PKI metu. Tai sukelia dažnesni poprocedūrinị skausmą.

Didesnis sistolinis arterinis kraujospūdis buvo susijęs su didesniu skausmo įverčiu procedūros metu. Toks rezultatas gali būti susijęs su sąveika tarp skausmą reguliuojančios ir kardiovaskulinès sistemų. Arterinis kraujospūdis padidèja kaip kompensacinis atsakas ị stresinị veiksnị. Esant nocicepciniams stimulams, aktyvuojama periferinè ir centrinè nervų sistemos. Dél simpatinès nervų sistemos aktyvacijos padideja periferinis pasipriešinimas, širdies susitraukimų dažnis ir išmetimo tūris. Ši atsaką sustiprina simpatinès nervų sistemos aktyvacija per pogumburio-hipofizès-antinksčių ašį. Šių veiksnių visuma didina arterinį kraujospūdi [15]. Su AKS padidejjimu gali būti susijęs stresas ir nerimas dèl procedūros baimès [16]. Yra žinoma, kad nerimas gali padidinti skausmo jutimą. Remiantis sistemine literatūros apžvalga, nustatyta, kad nerimas ar kitas psichologinis distresas yra stiprus ūminio skausmo predikcinis veiksnys [17]. Taip netiesiogiai galime susieti didesnị sAKS su procedūros metu nurodomu skausmu, tačiau tiksliam ryšiui išsiaiškinti reiktų atlikti tolimesnius tyrimus, itraukiant ir psichosocialinius veiksnius.

Šio tyrimo trūkumas - buvo atliktas vieno centro tyrimas ir tirta maža pacientų imtis. Nebuvo ištirti kiti veiksniai, kurie galèjo turèti ịtakos ūminiam skausmui, pvz.: ịvykusios komplikacijos, kitas jaučiamas skausmas, emociniai ir psichosocialiniai veiksniai, nuskausminamujų vartojimas. Siekiant patikslinti mūsų radinius, ateityje galima atlikti platesnius tyrimus, įtraukiant kitus veiksnius, galinčius daryti ịtaką ūminiam skausmui.

\section{Išvados}

1. Moterys procedūros metu ir visų vertinimų po intervencijos metu, skausmą įvertino reikšmingai didesniais balais, nei vyrai.

2. Ūminio skausmo transradialinės PKI metu ir po jos rizikos veiksniai buvo moteriškoji lytis, dislipidemija ir cukrinis diabetas.

\section{Literatūra}

1. Windecker S, Kolh P, Alfonso F, Collet JP, Cremer J, Falk V, et al. 2014 ESC/EACTS Guidelines on myocardial revascularization: the task force on myocardial revascularization of the European Society of Cardiology (ESC) and the European Association for Cardio-Thoracic Surgery (EACTS) developed with the special contribution of the European Association of Percutaneous Cardiovascular Interventions (EAPCI). European Heart Journal 2014;35: 2541-619.

https://doi.org/10.1093/eurheartj/ehu278

2. Kolkailah AA, Alreshq RS, Muhammed AM, Zahran ME, Anas El-Wegoud M, Nabhan AF. Transradial versus transfemoral approach for diagnostic coronary angiography and percutaneous coronary intervention in people with coronary artery disease. Cochrane Database of Systematic Reviews 2018;2018. https://doi.org/10.1002/14651858.CD012318.pub2 
3. Schoenfeld MS, Kassas I, Shah B. Transradial artery access in percutaneous coronary intervention for st-segment elevation myocardial infarction and cardiogenic shock. Current Treatment Options in Cardiovascular Medicine 2018;20:11. https://doi.org/10.1007/s11936-018-0607-1

4. Cheng KY, Chair SY, Choi KC. Access site complications and puncture site pain following transradial coronary procedures: a correlational study. International Journal of Nursing Studies 2013;50(10).

https://doi.org/10.1016/j.ijnurstu.2012.12.023

5. Lovich-Sapola J, Smith CE, Brandt CP. Postoperative pain control. Surgical Clinics of North America 2015;95:301-18. https://doi.org/10.1016/j.suc.2014.10.002

6. Kwon AH, Flood P. Genetics and gender in acute pain and perioperative opioid analgesia. Anesthesiology Clinics 2020;38:341-55. https://doi.org/10.1016/j.anclin.2020.01.003

7. Lindner A, Frieser M, Heide R, Wildner D, Neurath MF, Dauth $\mathrm{W}$, et al. Postinterventional pain and complications of sonographically guided interventions in the liver and pancreas. Ultraschall in der Medizin 2014;35(2):159-65. https://doi.org/10.1055/s-0032-1330497

8. Holme Ø, Bretthauer M, de Lange T, Seip B, Huppertz-Hauss G, Høie $\mathrm{O}$, et al. Risk stratification to predict pain during unsedated colonoscopy: results of a multicenter cohort study. Endoscopy 2013;45(9):691-6. https://doi.org/10.1055/s-0033-1344239

9. Vinik AI, Nevoret M-L, Casellini C, Parson H. Diabetic neuropathy. Endocrinology and Metabolism Clinics of North America 2013;42(4). https://doi.org/10.1016/j.ecl.2013.06.001

10. Peltier A, Goutman SA, Callaghan BC. Painful diabetic neuropathy. BMJ Publishing Group 2014;348. https://doi.org/10.1136/bmj.g1799

11. Poznyak A, Grechko AV, Poggio P, Myasoedova VA, Alfieri V, Orekhov AN. The diabetes mellitus-atherosclerosis connection: the role of lipid and glucose metabolism and chronic inflammation. International Journal of Molecular Sciences 2020;21. https://doi.org/10.3390/ijms21051835

12. Dharma S, Kedev S, Patel T, Gilchrist IC, Rao SV. The predictors of post-procedural arm pain after transradial approach in 1706 patients underwent transradial catheterization. Cardiovascular Revascularization Medicine 2019;20(8):674-7. https://doi.org/10.1016/j.carrev.2018.09.006

13. Fowkes FGR, Rudan D, Rudan I, Aboyans V, Denenberg JO, McDermott MM, et al. Comparison of global estimates of prevalence and risk factors for peripheral artery disease in 2000 and 2010: a systematic review and analysis. The Lancet 2013;382(9901):1329-40. https://doi.org/10.1016/S0140-6736(13)61249-0

14. Yano K, Kawabata A, Ikeda M, Suzuki K, Kaneshiro Y, Egi T. Hypercholesterolemia is associated with the subjective evaluation of postoperative outcomes in patients with idiopathic carpal tunnel syndrome who undergo surgery: a multivariate analysis. Plastic and Reconstructive Surgery. 2018;141(4):941-8. https://doi.org/10.1097/PRS.0000000000004228

15. Saccò M, Meschi M, Regolisti G, Detrenis S, Bianchi L, Bertorelli $\mathrm{M}$, et al. The relationship between blood pressure and pain. The Journal of Clinical Hypertension 2013;15(8):600-5. https://doi.org/10.1111/jch.12145

16. Munakata M. Clinical significance of stress-related increase in blood pressure: current evidence in office and out-of-office settings. Hypertension Research. Nature Publishing Group 2018;41: 553-69.

https://doi.org/10.1038/s41440-018-0053-1

17. Ip HYV, Abrishami A, Peng PWH, Wong J, Chung F. Predictors of postoperative pain and analgesic consumption: a qualitative systematic review. Anesthesiology 2009;111:657-77.

https://doi.org/10.1097/ALN.0b013e3181aae87a

\section{RISK FACTORS FOR ACUTE PUNCTURE SITE PAIN AFTER PERCUTANEOUS CORONARY INTERVENTION}

L. Brogienè, L. Grygalytė, B. Kakta, A. Macas

Keywords: acute pain risk factors, percutaneous coronary intervention.

Summary

Introduction. Our aim was to estabilish risk factors for acute pain after percutaneous coronary intervention (PCI).

Methods. We performed a single center prospective observational study of 136 patients that were admited to Hospital of Lithuanian university of health sciences Kaunas clinics for percutaneous coronary intervention during 2018-2020 period. Demographic data of enrolled patients was collected. Arterial blood pressure and heart rate was monitored during the procedure. Patients were asked to evaluate their pain in numerical pain rating scale from 0 to 10 during the procedure, 2 hours, 12 hours, 24 hours and 48 hours after the procedure. Collected data was analyzed using statistical methods.

Results. Females reported higher pain scores during all time points - during the intervention, $2 \mathrm{~h}, 12 \mathrm{~h}, 24 \mathrm{~h}$ and $48 \mathrm{~h}$ after the procedure $(p=0.003, p<0.001, p=0.010, p=0.022$ and $p=0.048$, respectively). Female gender was a risk factor for acute pain during the procedure $(p=0.018), 2 h(p=0.008), 12 h(p=0.023), 24 h$ $(\mathrm{p}=0.045)$ and $48 \mathrm{~h}(\mathrm{p}=0.046)$ after the procedure. Diabetes was risk factor for acute pain $24 \mathrm{~h}$ after the procedure $(\mathrm{p}=0.041)$. Dyslipidemia was found to be risk factor for acute pain during the procedure $(\mathrm{p}=0.024), 12 \mathrm{~h}(\mathrm{p}=0.018)$ and $24 \mathrm{~h}(\mathrm{p}=0.028)$ after the procedure. Higher systolic blood pressure was associated with pain experience during the PCI.

Conclusion. Females reported higher pain scores during PCI and at all time points after the PCI. Risk factors for acute pain after transradial PCI included female sex, dyslipidemia and diabetes.

Correspondence to: liuda.brogiene@kaunoklinikos.lt

Gauta 2021-05-07 